\title{
Effects of Gamma Irradiation on Ruminal Degradation of Samurai 1 Sweet Sorghum Bagasse
}

\author{
T. Wahyono*, N. Lelananingtyas and Sihono \\ Center for Isotopes and Radiation Application, National Nuclear Energy Agency, \\ Jl Lebak Bulus Raya 49, Jakarta 12440, Indonesia
}

\section{ARTICLE INFO}

\section{Article history:}

Received 10 December 2015

Received in revised form 10 October 2016

Accepted 10 October 2016

\section{Keywords:}

Gamma irradiation

In sacco

Ruminal degradation

Samurai 1

Sweet sorghum bagasse

\begin{abstract}
A B S T R A C T
The purpose of this study was to investigate the influence of gamma irradiation on dry matter, organic matter, and neutral detergent fiber degradability of Samurai 1 sweet sorghum bagasse, to facilitate its utilization in ruminant diets. Sorghum bagasse was obtained from Samurai 1 sorghum stem by-product after juice extraction. Gamma irradiation was carried out in a cobalt-60 irradiator in the Center for the Application of Isotopes and Radiation. Two polyethylene packages of samples were irradiated in gamma cell (Co-60) at doses of 50 and $100 \mathrm{kGy}$ in the presence of air. Treatments were untreated/unirradiated and 50- and 100-kGy gamma irradiation. Sample were incubated in the rumen for periods of 0, 8, 24, 48, and $72 \mathrm{~h}$ with in sacco method. The observed parameters were the degradations of dry matter (DM), organic matter (OM), and neutral detergent fiber (NDF). DM, $\mathrm{OM}$ and NDF degradation characteristics were also observed. DM degradation of $50 \mathrm{kGy}$ irradiation dose started higher than untreated samples after 24 hours incubation while OM degradation started higher than untreated samples after 48 hours incubation. DM and OM degradation of $100 \mathrm{kGy}$ irradiation started higher than untreated after 8 hours incubation. Gamma irradiation treatment of $50 \mathrm{kGy}$ and $100 \mathrm{kGy}$ could increase NDF degradation on 8 to 72 hours incubation. Irradiation was also capable to increase NDF degradation rate (c fraction) and ruminal effective degradation (ED) value on Samurai 1 sweet sorghum bagasse. Gamma Irradiation could break down the lignocellulose materials, break $\beta 1,4$ branch chain of cellulose and make it easily digested for rumen bacteria. The best dose of gamma irradiation for processing Samurai 1 sweet sorghum bagasse as a fiber source for ruminants was $100 \mathrm{kGy}$.
\end{abstract}

\section{INTRODUCTION}

The Samurai 1 is a sweet sorghum variety that is used in bioethanol industry. Sweet sorghum bagasse is a bioethanol industrial by-product that is potential for use as a fiber source for ruminants. This bagasse is derived from sweet sorghum stem after juice extraction so that the only remaining material mostly consists of fiber or complex carbohydrates. The high fiber content of sweet sorghum bagasse resulted in low palatability

\footnotetext{
* Corresponding author.

E-mail address: teguhwahyono@batan.go.id

DOI: http://dx.doi.org/10.17146/aij.2017.620
}

and poor nutrient utilization in ruminants [1]. The content of the fiber fraction like cellulose or hemicellulose is digested into glucose subsequently fermented into volatile fatty acids by rumen bacteria. Cellulose or hemicellulose is usually associated with a lignin matrix so that the enzymatic hydrolysis process in the rumen was not working effectively. The conversion of cellulose from lignocellulose to fermentable sugars is a decisive step for final product utilization which yet is a complex task [2].

Many studies have been done to improve the degradability of cellulose component in the feed. Yan et al. [3] investigated the effect of 
$\mathrm{NaOH}$ and $\mathrm{Ca}(\mathrm{OH})_{2}$ on cellulose degradation in sweet sorghum bagasse. Thanapimmetha et al. [4] investigated the use of Trichoderma harzianum to increase the depolymerization of lignocellulosic materials in sweet sorghum bagasse. The chemical-free hydrothermal pretreatment method was also used in the study. However, many methods above were dangerous for livestock and could cause chemical environmental pollution.

Ionizing irradiation, a process in which material exposed to gamma rays or electron beam, has been recognized as a reliable and safe method to improve the nutritive value of feeds [5,6]. Gamma irradiation is an alternative treatment to reduce the cell wall constituents, and depolymerize or delignify fibers in the plant.

Wang et al. [7] examined the effects of gamma irradiation as pretreatment of agricultural residues. Hahm et al. [8] have investigated the use of gamma irradiation on the nutrient composition, anti-nutrial factors, in vitro digestibility and ruminal degradation of whole cotton seed. From the above information, there has been no information yet on gamma irradiation effect on ruminal degradation kinetics of lignocellulosic materials used in sweet sorghum bagasse. Therefore, the aim of this study was to investigate the influence of gamma irradiation on dry matter (DM), organic matter $(\mathrm{OM})$, and neutral detergent fiber (NDF) degradability of Samurai 1 sweet sorghum bagasse to utilize them in ruminant diets.

\section{EXPERIMENTAL METHODS}

\section{Sample preparation}

Samurai 1 sorghum was harvested at 100 days. Sorghum bagasse was obtained from Samurai 1 sorghum stem by-product after juice extraction. Samples were dried at $60{ }^{\circ} \mathrm{C}$ and ground to pass a $2 \mathrm{~mm}$ screen. Gamma irradiation was carried out in a cobalt-60 irradiator in the Center for the Application of Isotopes and Radiation. Two polyethylene packages of samples were irradiated in a gamma cell (Co-60) at doses of 50 and $100 \mathrm{kGy}$ in the presence of air.

\section{Animal and diets}

Buffalo bulls with live weight of $300 \mathrm{~kg}$ fitted with rumen fistula were placed in $5 \mathrm{~m} \times 3 \mathrm{~m}$ pens with concrete floors that were cleaned regularly.
The buffaloes were fed a total mixed ration containing field grass and concentrate (50:50) based on dry matter (DM). The concentrate consisted of soybean meal (9\%), pollard (10\%), onggok (29\%), rice bran $(28.5 \%)$, soy pulp (15\%), lacto-mineral $(2 \%)$, urea $(1.5 \%)$, salt $(1 \%)$, lime $(1 \%)$, and molasses $(3 \%)$, and then mixed into horizontallymixer. Diet was formulated to contain $13 \%$ Crude Protein (CP)/kg of DM and fed twice daily at 08:30 and 15:30 h.

\section{In sacco ruminal degradability}

Nylon bags $(8 \mathrm{~cm} \times 15 \mathrm{~cm})$ with a pore size of $50 \mu \mathrm{m}$ were filled with approximately $4.5 \mathrm{~g}$ of the samples ground to pass a $2 \mathrm{~mm}$ screen. Bags filled with untreated, $50 \mathrm{kGy}$ and $100 \mathrm{kGy}$ irradiated samples were incubated in the rumen for periods of $0,8,24,48$ and $72 \mathrm{~h}$. All bags were simultaneously placed in the rumen, just before the buffaloes were offered their first meal in the morning $(<08: 30 \mathrm{~h})$. After retrieved from the rumen, the bags were washed with tap water and stored at $-20{ }^{\circ} \mathrm{C}$. After thawing, the bags were washed and dried in a turbing machine. The same procedure was applied to the $0 \mathrm{~h}$ sample periods. All residues were freezedried and analyzed for DM, OM, and NDF [9] to establish ruminal degradation kinetics of untreated and irradiated sorghum bagasse.

\section{Statistical analyses}

Reductions of DM or NDF content were fitted to the exponential model of Ørskov and McDonald [10] as $p=a+b\left(1-e^{-c t}\right)$. The constants $a$ and $b$ represent the soluble fraction and the fraction of non-soluble but degradable component which disappears at a constant fractional rate $c$ per unit time, respectively. The effective degradability $(E D)$ was calculated using $E D=a+b c /(c+k)$, estimated outflow rates $(k)$ of 0.02 and 0.05 [11]. The data was analyzed using completely randomized design by SPSS 16.00 with the following statistical model of $Y_{i j}=\mu+\alpha_{i}+\varepsilon_{i j}$, where $Y$ is the dependent variable, $\mu$ the overall mean, $\alpha_{i}$ the gamma irradiation effect and $\varepsilon_{\mathrm{ij}}$ is the residual error. Differences among treatments were separated using Duncan's Multiple Range Test [12].

\section{RESULTS AND DISCUSSION}

The degradation of DM, OM, and NDF was greater for irradiation-treated samples than for untreated Samurai 1 sorghum bagasse $(p<0.05)$ 
(Tables 1, 3, and 5). DM degradation under 50 and 100 kGy irradiation doses started higher than untreated samples after eight hours of incubation. The irradiation dose of $100 \mathrm{kGy}$ also resulted in a higher DM degradation than a $50 \mathrm{kGy}$ dose after 24 hours incubation (Table 1). The DM degradation characteristics of the $a$ and $b$ fractions were no different between irradiated and untreated samples, while for the $c$ fraction, the DM degradation was greater among irradiated samples than untreated samples (Table 2). The high rate of degradation ( $c$ fraction) resulted irradiated samples having a higher $E D$ of DM than untreated ones (Table 2).

Table 1. DM degradation (\%) of Samurai 1 sweet sorghum bagasse at different incubation periods

\begin{tabular}{lccccc}
\hline \multirow{2}{*}{$\begin{array}{l}\text { Irradiation dose } \\
\text { (kGy) }\end{array}$} & \multicolumn{5}{c}{ Ruminal incubation periods (h) } \\
\cline { 2 - 6 } Untreated & 0 & 8 & 24 & 48 & 72 \\
50 & $12.59^{a}$ & $18.62^{b}$ & $28.49^{c}$ & $39.75^{c}$ & $49.82^{c}$ \\
100 & $10.02^{b}$ & $21.92^{a b}$ & $32.64^{b}$ & $45.19^{b}$ & $55.96^{b}$ \\
\hline SEM & $12.11^{a}$ & $24.85^{a}$ & $36.12^{a}$ & $50.61^{a}$ & $61.65^{a}$ \\
\hline
\end{tabular}

DM: dry matter. Means with different superscripts within row are different $(p<0.05)$. Each value is a mean of three samples. SEM: standard error of the mean.

Table 2. DM degradation characteristics of Samurai 1 sweet sorghum bagasse at different incubation periods

\begin{tabular}{lcccc}
\hline \multirow{2}{*}{ Parameters } & \multicolumn{4}{c}{ Irradiation dose (kGy) } \\
\cline { 2 - 5 }$a(\%)$ & Untreated & 50 & 100 & SEM \\
\hline$b(\%)$ & 12.81 & 11.61 & 13.59 & 0.576 \\
$a+b(\%)$ & 82.27 & 59.01 & 66.89 & 3.850 \\
$c(/ \mathrm{h})$ & $0.010^{b}$ & $0.019^{a}$ & $0.019^{a}$ & 0.003 \\
Effective rumen degradation $(\mathrm{ED})\left(\mathrm{h}^{-1}\right)$ & & \\
$k=0.02$ & $36.67^{c}$ & $40.19^{b}$ & $45.25^{a}$ & 2.493 \\
$k=0.05$ & $24.78^{c}$ & $27.73^{b}$ & $31.39^{a}$ & 1.910 \\
\hline
\end{tabular}

DM: dry matter. Means with different superscripts within column are different $(p<0.05)$. Each value is a mean of three samples. SEM: standard error of the means. $a$ : washout fraction, $b$ : potentially degradable fraction, $c$ : rate of degradation. $k$ : estimated outflow rate.

The OM degradation of $50 \mathrm{kGy}$ irradiation started higher than untreated samples after 8 hours incubation. The OM degradation of $100 \mathrm{kGy}$ irradiation samples is higher than that of untreated samples at 8 and 72 hours of incubation (Table 3). The Gamma irradiation dose of $100 \mathrm{kGy}$ was more effective to improving OM degradation on Samurai 1 sorghum bagasse than $50 \mathrm{kGy}$ dose. Gamma irradiation treatment could also increase the $\mathrm{ED}$ value of $\mathrm{OM}$ on estimated flow rate $\mathrm{k}=0.02$, but only $100 \mathrm{kGy}$ gamma irradiation treatment that could increase $\mathrm{ED}$ value of $\mathrm{OM}$ on $\mathrm{k}=0.05$ (Table 4).

Table 3. OM degradation (\%) of Samurai 1 sweet sorghum bagasse at different incubation periods

\begin{tabular}{lccccc}
\hline \multirow{2}{*}{$\begin{array}{l}\text { Irradiation } \\
\text { dose (kGy) }\end{array}$} & \multicolumn{5}{c}{ Ruminal incubation periods (h) } \\
\cline { 2 - 6 } Untreated & $10.69^{a}$ & $20.22^{b}$ & $31.14^{b}$ & $44.55^{b}$ & $53.80^{c}$ \\
50 & $7.71^{b}$ & $22.43^{b}$ & $35.37^{a b}$ & $49.76^{a}$ & $58.90^{b}$ \\
100 & $10.50^{a}$ & $25.77^{a}$ & $39.51^{a}$ & $54.22^{a}$ & $65.52^{a}$ \\
\hline SEM & 0.607 & 0.893 & 1.429 & 1.543 & 1.730 \\
\hline
\end{tabular}

OM: organic Mmatter. Means with different superscripts within row are different $(p<0.05)$. Each value is a mean of three samples. SEM: standard error of the mean.

Table 4. OM degradation characteristics of Samurai 1 sweet sorghum bagasse at different incubation periods

\begin{tabular}{lcccc}
\hline & \multicolumn{3}{c}{ Irradiation dose (kGy) } & \\
\cline { 2 - 4 } Parameters & Untreated & 50 & 100 & SEM \\
\hline$a(\%)$ & $11.29^{a}$ & $9.01^{b}$ & $12.06^{a}$ & 0.915 \\
$b(\%)$ & 64.17 & 58.64 & 64.44 & 1.890 \\
$a+b(\%)$ & 75.46 & 67.66 & 76.51 & 2.792 \\
$c(/ \mathrm{h})$ & 0.018 & 0.027 & 0.024 & 0.003 \\
Effective rumen degradation $(\mathrm{ED})\left(\mathrm{h}^{-1}\right)$ & & \\
$k=0.02$ & $38.98^{c}$ & $42.03^{b}$ & $46.90^{a}$ & 2.307 \\
$k=0.05$ & $26.61^{b}$ & $29.06^{b}$ & $32.74^{a}$ & 1.781 \\
\hline
\end{tabular}

OM: organic matter. Means with different superscripts within column are different $(p<0.05)$. Each value is a mean of three samples. SEM: standard error of the mean. $a$ : washout fraction, $b$ : potentially degradable fraction, $c$ : rate of degradation. $k$ : estimated outflow rate.

Irradiation process could increase DM and OM degradation due to gamma irradiation's ability to cut lignohemicellulose and lignocellulose chain. This process increases the ratio of lignocellulose to crude fiber so as to accelerate the degradation rate of Samurai 1 sorghum bagasse. Takács et al. [5] reported that irradiation treatment has been used as a physical method to improve the nutritive value and digestibility of feedstuffs due to its effects on the lignocellulosic bonds. The digestibilty of organic matter and energy were increased. Irradiation increased the cellulose-to-crude fiber ratio in some agricultural residues (cottonwood, lentils straw, apple pruning products, and olive cake). Chemical composition analysis showed that gamma irradiation doses of 50, 100, 150, 200, 250, and $300 \mathrm{kGy}$ was able to degrade lignocellulose bonds as a pretreatment [13]. This study is in accordance with Tang et al. [14] that reported that gamma irradiation could improve rice straw OM degradation. This implies that gamma irradiation might change the fiber fraction of rice straw.

There are several opinions about the influence of gamma irradiation on DM degradation. It seems unrealistic to conclude that the feed value of 
irradiated samples is increased to the same extent. Fragments from lignin and monomers of carbohydrates may pass through the pores of bags. In different opinion, Kortei and Wiafe-Kwagyan [15] reported that gamma irradiation could break lignocellulose content of agro by-products to smaller molecules. Saini et al. [16] also stated that the aim of gamma irradiation pretreatment is to disrupt the tough lignocellulose complex to expose utilizable polymers. Pectic, cellulosic, and starch polysaccharides are degraded by cleavage of glycosidic bonds [17] so it could increase feed degradation value.

Gamma irradiation treatment of $50 \mathrm{kGy}$ and $100 \mathrm{kGy}$ could increase NDF degradation after a zero-hour incubation (Table 5). This treatment was also able to increase NDF degradation rate (c fraction) and ED value on Samurai 1 sweet sorghum bagasse (Table 6).

Table 5. NDF degradation (\%) of Samurai 1 sweet sorghum bagasse at different incubation periods

\begin{tabular}{lccccc}
\hline \multirow{2}{*}{$\begin{array}{l}\text { Irradiation } \\
\text { dose (kGy) }\end{array}$} & 0 & 8 & 24 & 48 & 72 \\
\cline { 2 - 6 } Untreated & $6.07^{b}$ & $7.64^{c}$ & $11.98^{c}$ & $23.63^{b}$ & $25.86^{c}$ \\
50 & $9.45^{a}$ & $11.99^{b}$ & $18.02^{b}$ & $26.25^{a}$ & $27.44^{b}$ \\
100 & $9.98^{a}$ & $15.57^{a}$ & $22.11^{a}$ & $27.66^{a}$ & $29.12^{a}$ \\
\hline SEM & 0.650 & 1.197 & 1.491 & 0.667 & 0.479 \\
\hline
\end{tabular}

NDF: neutral detergent fiber. Means with different superscripts within row are different $(p<0.05)$. Each value is a mean of three samples. SEM: standard error of the mean.

Table 6. NDF degradation characteristics of Samurai 1 sweet sorghum bagasse at different incubation periods

\begin{tabular}{lcccc}
\hline \multirow{2}{*}{ Parameters } & \multicolumn{3}{c}{ Irradiation dose (kGy) } & \\
\cline { 2 - 4 } & Untreated & 50 & 100 & SEM \\
\hline$a(\%)$ & $5.08^{b}$ & $8.81^{a}$ & $9.90^{a}$ & 1.460 \\
$b(\%)$ & $54.11^{b}$ & $25.11^{a b}$ & $21.52^{a}$ & 10.32 \\
$a+b(\%)$ & 59.19 & 33.92 & 31.43 & 8.870 \\
$c(/ \mathrm{h})$ & $0.009^{c}$ & $0.022^{b}$ & $0.039^{a}$ & 0.009 \\
Effective rumen degradation $(\mathrm{ED})\left(\mathrm{h}^{-1}\right)$ & & \\
$k=0.02$ & $19.34^{c}$ & $21.60^{b}$ & $23.99^{a}$ & 1.343 \\
$k=0.05$ & $12.04^{c}$ & $16.22^{b}$ & $19.21^{a}$ & 2.079 \\
\hline
\end{tabular}

NDF: neutral detergent fiber. Means with different superscripts within column are different $(p<0.05)$. Each value is a mean of three samples. SEM: standard error of the mean. $a$ : washout fraction, $b$ : potentially degradable fraction, $c$ : rate of degradation. $k$ : estimated outflow rate.

Gamma Irradiation treatment was able to reduce NDF content on Samurai 1 sweet sorghum bagasse. Lower NDF content caused by the response to the gamma irradiation treatments is attributed to the type of the treated samples, the structure of the lignin materials, and the cellulose and lignin contents of the residue. Gamma irradiation pretreatment also reduce NDF, $\mathrm{ADF}$, and $\mathrm{OM}$ contents [14]. Kim et al. [13] showed that gamma ray irradiation on Brachypodium distachyon decreased the cell wall yield, lignin content, and neutral sugar content. Several other researchers reported that irradiation can be used to improve the degradation kinetics of the DM and NDF of wheat straw. DM and NDF degradability increased linearly $(P<0.001)$ with increases in irradiation dose [18]

This study examined the effects of gamma irradiation on in sacco ruminal degradation. This study found that DM, OM, and NDF ruminal degradation of Samurai 1 sorghum bagasse could increase with gamma irradiation treatment. In another study, it was reported that high doses of electron beam irradiation ( 250 and $500 \mathrm{kGy}$ ), the effective degradability of NDF at a ruminal passage rate $0.05 / \mathrm{h}$ increased by $11 \%$ and $20 \%$ respectively [19]. However, morphological, structural, and functional changes in samples are governed by the intensity and duration of the gamma irradiation [20]. The results of this study need to be supported by testing the effects of gamma irradiation on Samurai 1 sorghum bagasse with other experiments. In vitro and in vivo digestion experiments seem necesarry to evaluate this industrial by-products. Thus, if gamma irradiation is to have a role in the treatment of Samurai 1 sorghum bagasse, it must be more useful, cheaper, and applicable than physical and chemical treatment methods.

\section{CONCLUSION}

Gamma Irradiation treatment increased ruminal DM, OM, and NDF degradation. Gamma irradiation is able to break down the lignocellulose materials, break $\beta 1,4$ branch chain of cellulose and make it easily digested for rumen bacteria. The best dose of gamma irradiation for processing Samurai 1 sweet sorghum bagasse as a fiber source for ruminants was $100 \mathrm{kGy}$. Further study is needed to investigate the influence of higher dose of gamma irradiation (> $100 \mathrm{kGy}$ ) on Samurai 1 sweet sorghum bagasse degradability.

\section{ACKNOWLEDGMENT}

The author wish to thank Ir. Suharyono, M.Rur.Sci, Dr. Irawan Sugoro, Shintia Nugrahini Wahyu Hardani, AMd. and all members of the Animal Production Group. Gratitude is also expressed to Mr. Udin Siman and others who helped in the field during this project and those who contributed to this paper. 


\section{REFERENCES}

1. C.V. Seshaiah, Y.R. Reddy, S.J. Rao et al., J. Adv. Vet. Anim. Res. 1 (2014) 224.

2. B. Dalecka, M. Strods and L. Mezule, Agron. Res. 13 (2015) 287.

3. Z. Yan, J. Li, S. Li et al., Energy Procedia 61 (2014) 1957.

4. A. Thanapimmetha, K. Vuttibunchon, M. Saisriyoot et al., World Renewable Energy Congress Proc. (2011) 389.

5. P. Shawrang, A.A. Sadeghi, M. Behgar et al., Food. Chem. 125 (2011) 376.

6. M. Hajipour, A. Nikkhah, P. Shawrang et al., IJBPAS. 3 (2014) 2500.

7. K.Q. Wang, X.Y. Xiong, J.P. Chen et al., Biomass and bioenergy 46 (2012) 301.

8. S.W. Hahm, H. Son, W. Kim et al., J. Anim. Sci. Technol. 55 (2013) 123.

9. U. Krishnamoorthy, RCA Training Workshop on In Vitro Techniques for Feed Evaluation, The International Atomic Energy Agency, Jakarta, April 23-27 ${ }^{\text {th }}$ (2001) 17.

10. E.R. Ørskov and I. McDonald, J. Agr. Sci. Camb. 92 (1979) 499.
11. Anonymous, Agricultural and Food Research Council, Energy and Protein Requirements of Ruminants, in: AFRC Technical Committee on Responses to Nutrients, CAB International, Wallingford, UK (1993) 175.

12. R.G.D. Steel and J.H. Torrie, Principles and Procedures of Statistics, $2^{\text {nd }}$ ed., McGraw-Hill, New York (1980) 633.

13. J.Y. Kim, C.S. Na and D.S. Kim, Cellulose 22 (2015) 2419.

14. S.X. Tang, K.Q. Wang, Z.H. Chong et al., J. Food Agric. Environ. 10 (2012) 459.

15. N.K. Kortei and M. Wiafe-Kwagyan, Croat. J. Food Tech. Biotech. Nut. 9 [2014] 83.

16. A. Saini, N.K. Anggarwal, A. Sharma et al., Biotechnol. Res. Int. (2015) 1.

17. R.S. Orozco, P.B. Hernandez, N.F. Ramirez, Energies 5 [2012] 3051.

18. P. Shawrang, A.A. Sadeghi, J. Ahmadpanah, Iran J. App. Anim. Sci. 3 (2013) 25.

19. P. Shawrang, A. Majdabadi, A.A. Sadeghi, Turk. J. Vet. Anim. Sci. 36 (2012) 527.

20. I. Piri, M. Babayan, A. Tavassoli et al., Afr. J. Microbiol. Res. 5 [2011] 5806. 